\title{
Demographic Determinants of Primary Health Care Services Utilization among Childbearing Women in Bayelsa State
}

\author{
Aluku, Prince Eregha, Dr. G. O. Ekenedo* \\ Department of Human Kinetics \& Health Education, faculty of Education, university of Port Harcourt \\ *Corresponding Author: Dr. G. O. Ekenedo, Department of Human Kinetics \& Health Education, \\ faculty of Education, university of Port Harcourt
}

\begin{abstract}
This study investigated the demographic determinants of Primary Health Care (PHC) services utilization among childbearing women in Bayelsa State. Two research questions as well as two responding hypotheses guided the study. The study adopted descriptive survey design. A sample of 1,875 women were selected through multistage sampling procedure. The instrument used for data collection was a selfstructured 36 item questionnaire titled Demographic Determinants of Health Care Services Utilization Questionnaire (DDHCSUQ). The reliability of instrument was established using Pearson Product Moment Correlation (PPMC) which yielded a coefficient value of 0.72. Mean, standard deviation and ANOVA was used to analyze the data. The findings of the study revealed that age and level of income are significant determinants of primary health care services utilization among childbearing women in Bayelsa State. Based on the findings of the study, it was recommended among others that the government should make primary health care services affordable and accessible to all women in other to improve primary health care services utilization. Moreso, there should be mass sensitization of women on available maternal health care services at primary health care facilities.
\end{abstract}

Keywords: Age, Level of Income and Primary Health Care (PHC) Services Utilization

\section{INTRODUCTION}

The attainment of good health is the best asset for every individual to function optimally in the society. The health care delivery goal of any country cannot be actualized without adequate assessment of the health facilities by people they are meant for. There have been issues of availability of health care facilities and utilization of health services in developing countries including Nigeria. Both issues have been of great concern in health sector and the public in general. World Health Organization - WHO (1948), defined health as a state of complete physical, mental and social wellbeing and not merely the absence of disease or any infirmity (Nordqvist, 2017). The researcher stated furthermore that the existence of health services was to ensure that people obtain optimal level of health.

During the post-colonial era, the developing countries experience a type of health care that was hospital based and curative in nature which were concentrated more in the urban areas at the expense of the rural dwellers (Bryant \& Richmond, 2008). They also stated further that this disparity in the health sector led WHO to shift its attention from areas such as malaria eradication to develop the basic health services before the Alma Ata Declaration in 1978. In similar vein, the Director General of the then WHO during the 28 World Health Assembly (WHA) conference of 1975, observed the short comings of orthodox medicine and its implications on the health status of people in the developing world (Balarabe, 2014). The researcher also observed that health facilities were concentrated in urban areas and non existence in rural communities and that it was necessary to plan health services that will bridge the gap and have positive impact on the citizens. According to Balarabe (2014), in order to bridge this gap, the proposal of two approaches; "basic health services and primary health care were accepted as the bases to meet the health care needs of majority of the population and were formulated into policy by UNICEF / WHO.

Primary Health Care (PHC) is the entry point of individuals, the family, and the community with the national health care delivery system thereby bringing health services as close as possible to where 
people live and work, and it provides the platform for continuity of care where the need arise (WHO, 2018). The Alma Ata Declaration during the "International Conference on Health for All and Primary Health Care" held between $6^{\text {th }}$ to $12^{\text {th }}$ September, 1978 defined primary health care as an essential health care based on practical, scientifically sound and socially acceptable methods and technology made universally acceptable to individuals and families in the community through their full participation and at a cost that the community and country can afford to maintain at every stage of their development in the spirit of self - reliance and self - determination (Gupta \& Ghai, 2007). Jayachandran (2018), asserted that during the Alma Ata conference, the WHO view on health services, "particularly public health care policies and the roles to be played by the government for the wellbeing of the citizens were outlined in detail". Furthermore, the researcher stated that it was the first time that access to affordable health services was recognized as a "human right".

Laverty (2017) and Kullabs (2019) asserted that the Alma Ata Declaration also outlined the following eight essential components of PHC as a means of providing health care globally;

1. Public health education on locally endemic diseases in order to prevent and control them. Good health is very important for us to live a worthwhile human life. Good health enables us to be educated and pursue any other economic activity in the society. Health education is a means of transmitting basic health information to people that will enable them to promote the way of healthy living and to solve basic health problems.

2. Adequate nutrition. Proper nutrition is very necessary for us to live a healthy. Supply of enough food and good management enable us to eat balance diet. It is because of lack of balance diet that give rise to malnutrition and other related diseases. Adequate nutrition is therefore an important aspect of primary health care (PHC).

3. Adequate supply of safe drinking water and basic sanitation. Supply of safe water and basic sanitation are closely related. If there is no sufficient supply of adequate water, there will be poor sanitation. Lack of supply of adequate water and poor sanitation make us victims of preventable diseases such as diarrhea, cholera, typhoid, round worms, dysentery, malaria etc. provision of water in sufficient quantity and basic sanitation is the only panacea for us to be free from the preventable diseases enumerated above in order for us to maintain good health thereby improving our health status.

4. Maternal and child health care including family planning. Mothers and children are vulnerable to diseases. Provision of maternal and child health services is very important to improve the health status of mothers and children,

5. Immunization services to prevent vaccine preventable disease, Immunization are widely accepted as intervention for protection against a number of communicable diseases. Unfortunately, the practice is low in developing countries due to lack of knowledge, poor economic status and concentration on sophisticated curative health services. Immunization is the only preventive measure against diseases like tuberculosis, tetanus, whooping cough, poliomyelitis, meningitis, measles, yellow fever, hepatitis B, pneumonia etc. Currently, many states in Nigeria has been declared states of emergency on immunization in order to strengthen immunization activities.

6. Treatment of minor ailments. Treatment of minor ailments at the primary health care level is one of the important components of PHC. Lack of prompt treatment has led to the dead of many rural dwellers. Primary health care workers are therefore trained to cater for minor conditions and make referral to appropriate quarters for condition that they cannot handle. This act leads to reduction of morbidity and mortality in areas where such services are available.

7. Provision and supply of essential drugs. The supply of essential drugs to primary health care centres is also one the important aspects of primary health care. The aim is to ensure the availability of essential drugs at the PHC centres regularly to cater for conditions diarrhea, fever, pains, prevention and treatment of other minor ailments.

8. Locally endemic disease control. The identification and control of endemic diseases in a community is also one of the very important aspects of primary health care. The control and eradication of such diseases will enhance the health status of the people. 
As the closest level of care in the community, primary health care professionals are often the first point of contact with patients. They help to coordinate patients care with other providers and also help patients who require more specialized medical attention to navigate the health care system. They provide holistic and personalized care for patients of different age groups (WHO, 2017). Similarly, Ministry of Health (2017) also affirmed that primary health care workers render services such as management of upper respiratory tract infections, diabetis and keep the population health through the provision of preventive measures as health screening. Ministry of Health (2014), stated that common services provided at primary health care level include; outpatient medical treatment, medical follow ups after discharge from hospitals, immunization, health screening and education, diagnostic and pharmaceutical services, and referral services. Furthermore, the services were designed to meet the health needs of the community through the use of available health facilities with health manpower carrying out their professional duties (Moronkola \& Obiechina, 2010).

Primary health care (PHC) is said to be a grass root approach to provide quality health care services to communities. Because of the importance attached to it, the Federal Government of Nigeria launched the PHC plan in the National health policy of 1988 as the cornerstone of the Nigerian health system as part of effort to improve equity in access and utilization of basic health services (Sherif, 2016). According to Ogundeji (2002), 'the first serious attempt to put primary health services in place in Nigeria was in 1975. The author further stated that it was during this period that dispensaries, maternity homes and health centers were built all over Nigeria to promote, prevent, detect diseases early and manage health problems within the community. In similar vein, Sherif (2016) reported that there have been three attempts in Nigeria at evolving this people and community-oriented health system. The first attempt occurred between 1975 and 1980 when the Basic Health services Scheme (BHSS) was introduced. The second attempt led by late Professor OlukoyeRansome - Kuti occurred between 1986 and 1992 which witnessed the development of model Primary Health Care Centers in 52 Local Government Areas in Nigeria. Furthermore, the author stated that the third attempt to make Primary Health Care Services accessible to the grass root was marked with the establishment of the National Primary Health Care Development Agency (NPHCDA) in the year1992.

Oladipo (2014), identified the determinants of utilization of available health services in a community as proximity, cost, and availability of required services, health insurance, staff attitude and quality of service among others. In similar vein, Okonofua et al (2018) in their study identified distance, costs and quality of care as limiting factors to the utilization of health services and that these factors needed to be addressed properly in order to optimize women utilization of PHC services. The determinants of utilization of PHC services are diverse. Oladipo (2014), explained that they could be viewed in three folds; predisposing factors that rendered health services favorable inclined and susceptible such as age, sex, religion, occupation, culture, attitude, belief, and health education. Secondly, determinants described as enabling factors refer to variables which engender the use of health services such as proximity, availability, costs, motivational benefits, free healthcare, and health insurance. Finally, factors which discourage the utilization of health services such as negative attitude of staff, long distance, high cost of treatment, long waiting to receive care and incompetent staff were referred to as disabling factors. Family doctors (2018), also stated that the condition that we live, learn, work, and play, are referred to as social determinants of health. These conditions can possibly influence the health and well-being of the individual and the community they live. Furthermore, they also asserted that social determinants include things like level of education, your exposure to violence, and the way your community is designed, and if health care is accessible to you. They opined that the factors enumerated above can affect your ability to take part in healthy behaviors, and this affects your health.

PHC services are intended to be qualitative, affordable, accessible and available to everyone especially to people residing in the rural areas with a view to improve the health status of people globally. PHC services utilization is a key factor for planning and management. Utilization is the extent to which a given group uses a particular service within a specific period (Babalola \& Fatusi, 2009). In similar vein, Abugu, Eze and Nwanneka (2018), explained that utilization is the use of something for practical purposes. Utilization in this present study refers to the use of available maternal primary health care services by women of childbearing age to improve their health status thereby reducing maternal mortality rate. World Health Organization (2017), defined reproductive age as women between the age bracket of 15 to 49years. According to Olise (2007), women of the reproductive age are the most vulnerable members of the community and that in line with the tenets of 
PHC; they deserve special attention to make them realize their full potentials. Therefore, they ought to be sensitized to utilized health services available in their community. Maternal mortality could be described as the death of women of child bearing age resulting from pregnancy or child birth and not necessarily an accidental cause (Walker, 2018).

Walker (2018), reported that the 'Nigerian's maternal mortality rate was 800 per 100,000 live birth in 2008 but it has dropped to 560 per 100,000 live birth and that it has not reached the 210 per 100,000 live birth world target, but it has slightly dropped below the West and central African sub - region target of 590 per 100.000 live birth. Shuaib (2019), who at the same time is the executive director of National Primary Health Care Development (NPHCDA) Agency, reported that "Every day in Nigeria, approximately 145 women die from preventable causes related to pregnancy and childbirth, the researcher emphasized that this could be compared to one (1) Boeing 737-300 series airplane, fully loaded with 145 women crashing every day in Nigeria killing everyone on board". According to the director, 2,300 children under five years also die every day mainly from diseases that are preventable. In view of the above scenario and in the phase of limited efforts to reverse the trend, the director therefore declared a state of public concern on maternal, new born and child deaths occurring at Primary Health Care (PHC) and community levels in Nigeria. In order to tackle these preventable deaths, the director proposed the establishment of a National Coordination Centre within the NPHCDA to provide over sight on reproductive, maternal, neonatal, child, adolescent health plus nutrition activities at PHC level.

The safe motherhood initiative was also launched to improve maternal health and reduce maternal mortality and from thenceforth, it has been the focus of many international health programs. For instance, improving maternal health is the $5^{\text {th }}$ of the Millennium Development Goals (MDGs). This goal calls for a 75 percent reduction in maternal mortality between 1990 - 2015. USAID also targets reducing maternal mortality by 30 percent across all its assisted countries (USAID,2011). The main objective of safe mother hood is ensuring that all women receive the care they need throughout pregnancy and child birth (WHO/UNICEF, 2003). Ante natal care is one of the key interventions needed to meet the objective of safe mother hood and the MDG.

According to WHO/UNICEF (2003), ante natal care (ANC) is the care a woman receives during pregnancy which helps to ensure healthy outcomes for women and their new born baby. Furthermore, WHO/UNICEF (2003) also stressed that antenatal care is given to a pregnant woman and her baby starting from the time of conception up to the delivery of the baby. Furthermore, ANC services involve regular monitoring of the woman and her baby throughout pregnancy by various means including a variety of routine regular examination and some other simple tests. In line with this global objective and to encourage mothers to utilize available maternal health care services, the Bayelsa State Government has declared that pregnant women in the state will be given adequate attention until they safely put to bed. Professor Ebitimitula Etebu, the Bayelsa State commissioner for health reported that the government was determined to resolve the issue of maternal and infant mortality currently ravaging Bayelsa State. The commissioner explained further that the fatality cases during pregnancy and child birth could have been avoided if the women were properly catered for. He stated further that the Bayelsa State government will be willing to provide everything needed in the state primary and tertiary health facilities to cater for the women (Oduma, 2018).

Etebu, (2018), also reported that Bayelsa State currently has the poorest record of maternal mortality rate among the states in the South - South region of Nigeria and that according to available statistics from the 2013 Nigerian Demographic and Health survey, the maternal mortality rate was 1,8 70 per 100,000 live births. These deaths would have been prevented if the women of child bearing age were utilizing available PHC services (Odetola et al, 2015). Idris, Sambo and Ibrahim (2013) in their study titled " Barriers of utilization of maternal health services in a semi - urban community in northern Nigeria" asserted that low level of utilization of maternal health services (MHS) is a major factor responsible for high maternal mortality in north western region of Nigeria. The researchers further declared that the high mortality rate in Nigeria varies from region to region and that it was higher in rural areas than urban areas. The study also revealed that the North West region has mortality rates that are six times higher than the south west. It is against this back drop that the researcher investigated the demographic determinants of PHC services utilization among childbearing women in Bayelsa State of Nigeria. 


\section{AIM AND OBJECTIVES OF THE STUDY}

The study investigated demographic determinants of Primary Health Care (PHC) services utilization among childbearing women in Bayelsa State of Nigeria. Specifically the study achieved the following;

1. Find out whether age is a determinant of PHC services utilization among childbearing women in Bayelsa State

2. Establish whether income is a determinant of PHC services utilization among childbearing women in Bayelsa State.

\subsection{Research Questions}

The following research questions guided the study;

1. How could age be a determinant of PHC services utilization among childbearing women in Bayelsa State?

2. How could level of income be a determinant of PHC services utilization among women of childbearing age in Bayelsa State?

\subsection{Hypotheses}

1. Age is not a significant determinant of PHC services utilization among women in Bayelsa State.

2. Income is not a significant determinant on the level of PHC services utilization among women in Bayelsa State.

\section{Methodology}

The study adopted the descriptive survey research design, using the cross-sectional approach. The sample size for the study consists of 1,875 women of child bearing age in all the 8 local Government Areas (LGAs) of Bayelsa State. Multistage sampling procedure was used to select the respondents from the two hundred and eleven (211) health facility-based communities distributed across the eight LGAs of the State (National Primary Health Care Development Agency (NPHCDA), 2018). Each LGA was considered as a stratum. A self developed questionnaire titled Demographic Determinants of Health Care Services Utilization Questionnaire (DDHCSUQ) was used for data collection. The reliability of the instrument was done using Pearson Product Moment Correlation which yielded a reliability coefficient of 0.72 . Mean, standard deviation and ANOVA were used to analyze the data.

\section{Result PReSEntation}

Research Question 1: How could age be a determinant of PHC services utilization among childbearing women in Bayelsa State?

Hypothesis 1: Age is not a significant determinant of PHC services utilization among women in Bayelsa State.

Table1. ANOVA of age as a determinant of PHC services utilization among child bearing women in Bayelsa State

\begin{tabular}{|l|l|l|l|l|l|}
\hline Determinants & Sum of Squares & df & Mean Square & F & Sig. \\
\hline Between Groups & 162252.148 & 3 & 54084.049 & 1336.075 & .000 \\
\hline Within Groups & 60557.796 & 1496 & 40.480 & & \\
\hline Total & 222809.944 & 1499 & & & \\
\hline
\end{tabular}

Table 1 shows the one-way ANOVA of age as a determinant of PHC services utilization among childbearing women in Bayelsa State. The sum of squares for between groups is 162252.148, degree of freedom, 3 and mean square is 54084.049, while the sum of square for within groups is 60557.796 , degree of freedom, 1496 and mean sum of square is 40.480 . The total sum of square and degree of freedom are 222809.944 and 1499. The F-value of the ANOVA is 1336.075 at $\mathrm{P}=0.000$. Since $\mathrm{P}$ $(0.000)<0.05$ alpha level, therefore the null hypothesis is rejected. This implies that, age significantly determine PHC services utilization among childbearing women in Bayelsa State.

Research Question 2: How could level of income be a determinant of PHC services utilization among women of childbearing age in Bayelsa State? 
Hypothesis 2: Income is not a significant determinant on the level of PHC services utilization among women in Bayelsa State.

Table2. ANOVA of level of income as determinant of the utilization of PHC services among child bearing women in Bayelsa State

\begin{tabular}{|l|l|l|l|l|l|}
\hline Monthly Income & Sum of Squares & Df & Mean Square & F & Sig. \\
\hline Between Groups & 177710.657 & 3 & 59236.886 & 525.399 & .000 \\
\hline Within Groups & 168668.742 & 1496 & 112.746 & & \\
\hline Total & 346379.399 & 1499 & & & \\
\hline
\end{tabular}

Table 2 shows that the one-way ANOVA of level of income as determinant of the utilization of PHC services among child bearing women in Bayelsa State. The sum of squares between groups is 177710.657 , degree of freedom, 3 and mean square is 59236.886. The sum of square within groups is 168668.742, degree of freedom, 1496 and mean sum of square is 112.746. Total sum of square and degree of freedom are 346379.399 and 1499. The F-value of the ANOVA is 525.399 at $\mathrm{P}=0.000$. Since P $(0.000)<0.05$ alpha level, we reject the null hypothesis. That is, level of income significantly determines the utilization of PHC services among child bearing women in Bayelsa State.

\subsection{Summary of Findings}

The findings of the study are summaries as follows;

1. Age was found significant to be a determinant of PHCS utilization among the women of childbearing age in Bayelsa State.

2. Level of income was found to be a strong determinant of PHCS utilization among the women of childbearing age in Bayelsa State.

\subsection{Discussion of Findings}

\subsubsection{Age and Primary Health Care Services Utilization}

The findings of the study revealed that age was a significant determinant of Primary Health Care (PHC) services utilization among the women of childbearing age in Bayelsa State. Further analysis of the result showed that women 25 years and above utilize Primary Health Care (PHC) services to a high extent while there was low utilization among younger women in Bayelsa State. The finding of the present study is in agreement to an earlier study by Khan, Khan and Khan (2013) who found out that age is determinant factor affecting the utilization of maternal and child health services (MCHS) in district Swat, KPK Pakistan. Also, Onasoga, Osaji Achi, Amos and Chinedu (2013), who found out that age is a significant determinant of primary health care services. They further explained that awareness is a barrier to the utilization of maternal health care services among reproductive women in Amassoma community, Bayelsa State. The findings of the study however, disagrees with the study by Habtom, (2017), who found out that women who had pregnancy at young age were likely to use antenatal services, receive skilled delivery and attend post-natal clinic than the older women in Eriteria.

\subsubsection{Level of Income and Primary Health Care Services Utilization}

The findings of the study showed that level of income is a strong determinant of Primary Health Care (PHC) services utilization among women of childbearing age in Bayelsa State. The null hypothesis was rejected. The findings of the present study is in agreement with an earlier study by Oladipo (2014), and Okonofua et al (2018) who found out that income level significantly determines the utilization of Primary Health Care (PHC) services among women of childbearing age. Also, Family Doctors (2018) found out that the income level of an individual has significant influence on the health of the person as well as the access to health care facilities. Habtom, (2017) also found that women with higher income utilize maternal and child health services than women with little or no source of income.

\section{CONCLUSION AND RECOMMENDATION}

Based on the findings of this study, it was concluded that age and level of income are determinants of Primary Health Care (PHC) services utilization among childbearing women in Bayelsa State. It was in the light of this that the following recommendations are made; 
1. Government should make PHC services affordable and accessible to all women as a matter of urgency to reduce the high rate of maternal mortality currently experienced in the state.

2. There should be mass sensitization of women in the Primary Health Care facilities as regards available maternal and child health services at the health facility in other to improve access and satisfactory usage of such services.

3. There should also be constant supportive supervision of PHC activities in the facilities in other to identify problems that might militate against the effective utilization of available maternal health services and address essential areas that will need improvement.

\section{REFERENCES}

[1] Balarabe, D. (2014) Synopsis of Community Health Practice in Nigeria, Zaria, Ahmadu Bello University Press, Limited.

[2] Bryant, J. H. \& Richmond, J.B. (2008) Alma - Ata and Primary Health Care: An Evolving Story. Retrieved from https://www.google.com/search/source/=hp\&e:=px7dw6-3jipokw... On the $3^{\text {rd }}$ November, 2018.

[3] Chinyere, C.O., Cajetan, I.I.., Nwimo, I.O., \& Onwunaka, C. (2015). Extent of Utilization of Antenatal Care Services Among Childbearing Mothers in Anambra State of Nigeria. Retrieved fromwww.rroij.com $>$ open access $>$ extent of ... on the $25^{\text {th }}$ of May, 2019. Dapaah, J.M. (2019). Socio cultural Determinants of the Utilization of Maternal Health Care. Retrieved from https://www.hindawi.com.aph on the $12^{\text {th }}$ of September, 2019.

[4] Etebu E. (2018). Bayelsa, Worst Maternal Mortality in South - South, Nigeria, Tribune. Retrieved from www.tribuneonlineng.com.bay... On the $16^{\text {th }}$ March, 2018.

[5] Gupta, P. \&Ghai, O.P.(2007). Textbook of Preventive and Social Medicine. India, Diamond Agencies Pvt. Limited.

[6] Habtom, G.K. (2017) Factors Affecting The Use of Maternal and Child Health Services I Eritrea, J Complement Med Alt Health Care. 2(3): 555589.DOI: 10. 19080/JCMAH. Retrieved from https://www.semanticscholar.org> paper on $15^{\text {th }}$ of January, 2019.

[7] Idris, S.H., Sambo, M.N., \& Ibrahim, M.S. (2013). Barriers to Utilization of Maternal Health Services in a Semi - Urban Community in Northern Nigeria: The Client Perspective. Niger Med J.com/article.asp?issn $=0300-1652$ years $=2013$ volume $=54$ issue $=1$ : page $=32$ : aulast $=$ Idris on the $15^{\text {th }}$ of January, 2019.

[8] Jayachandran, N. (2018). Alma Ata Declaration: 40 years on, what has this public health initiative achieved? Retrieved from https://www.thenewsminute.com>article on the $27^{\text {th }}$ of January, 2018.

[9] Khan, N., Khan, N. \& Khan, S. (2013). Factors Affecting Utilization of Maternal And Child Health Services; District Swat KPK Pakistan, International Journal of Innovative Research and Development. Retrieved from www.ijird.com on the $10^{\text {th }}$ of August, 2018.

[10] Laverty, S. (2017).8 Components of Primary Health Care. https://pocketsense.com/8-componentsof primary- health -care. Retrieved on the $5^{\text {th }}$ November, 2017.

[11] Ministry of Health (2014).Ministry of Health Singapore. Retrieved from https//www.moh.gov.sg.primary care. On 27/7/2017

[12] Ministry of Health (2017). Primary Health Care Services. Retrieved from https://www.moh.gov.sg on the $117^{\text {th }}$ of July, 2018.

[13] Moronkola, O.A. \& Obiechina, G.O.(2010). Determinants of Students Utilization of University of Ibadan Health Services in Ibadan, Nigeria, Nigerian School Health Journal Vol.22 page 65.

[14] Nordqvist, C. (2017) Health: What Does Good Health Really Mean? Retrieved from https://www.medical news today.com/articles/150999 php on the $17^{\text {th }}$ of November, 2018.

[15] NPHCDA, (2018).Functional Primary Health Care Facilities in Bayelsa State, State Emergency Routine Immunization Coordinating Centre, SMOH. Yenagoa, Bayelsa State.

[16] Odetola, D. T. et al (2015). Health Care Utilization among Rural Women of Child Bearing Age: A Nigerian Experience. Department of Nursing, University of Ibadan, Ibadan. Retrieved from http://www.panafrican-med-journal.com/content/article/20/151/full

[17] Ogundeji, M.O (2002). Background and Status of PHC Activities by Y 2000 in Nigeria. Ibadan, XANFUN limited No.26 Oyo Road, Opposite University of Ibandan

[18] Okonofua, F., Ntoimo, L., Ogungbangbe, J., Anjorin, S. Imongan, Wilson and Yaya, S. (2018). Determinants of Women's Utilization of Primary Health Care for Skilled Pregnancy Care in Rural Nigeria. Retrieved from https://doi.org/10.1186/s/2884-018-17304 on the 5/7/18. 
[19] Oladipo, J.A (2014). Utilization of Health Care Services in Rural and Urban Areas. A Determinant Health Care Delivery System. Retrieved from https//www.ncbi.nim.nih.gov.article 27/7/17.

[20] Olise, P. (W2007). Primary Health Care for Sustainable Development, Ibadan, Omoade printing press.

[21] Onasoga, A. C., Osaji, T. A., Alade, O. A., \&Egbuniwe, M. C. (2014). Awareness and Barriers to Utilization of Maternal Health Care Services Among Reproductive Women in Amassoma Community, Bayelsa State, International Journal of Nursing and Midwifery, vol. 6 (1), pp. 10 -15. Retrieved from https://www.academicjournals.org/unm on 13th of March, 2018.

[22] Safe Motherhood, (2015).Retrieved from www.safemotherhood.

[23] Sherif, O.S (2016).History of PHC in Nigeria. Retrieved from Google weblight.com/i?u = http.//naija quest .history. prim on the 29/7/17.

[24] Walker, D. (2018). Improving maternal and Childbirth through Primary Health Care Implementation in Bayelsa State. Retrieved from https://creativecommons.org./licenses/by/4.0/ on the $4^{\text {th }}$ of May, 2019.

Citation: Aluku, Prince Eregha, Dr. G. O. Ekenedo. "Demographic Determinants of Primary Health Care Services Utilization among Childbearing Women in Bayelsa State" International Journal of Humanities Social Sciences and Education (IJHSSE), vol 7, no. 4, 2020, pp. 143-150. doi: http://dx.doi.org/10.20431/23490381.0704014.

Copyright: (C) 2020 Authors. This is an open-access article distributed under the terms of the Creative Commons Attribution License, which permits unrestricted use, distribution, and reproduction in any medium, provided the original author and source are credited. 